\title{
RESULTS OF SURGICAL TREATMENT IN HIRSCHSPRUNG'S DISEASE*
}

\author{
BY \\ JARMO KOSTIA \\ From the Children's Hospital of the Helsinki University Clinic
}

Since 1948, a total of 89 patients with an aganglionic megacolon have been treated at the Children's Hospital of the Helsinki University Clinic. There were 68 cases of Hirschsprung's disease, and in 21 cases the anomaly had developed with anal atresia. In nine cases Hirschsprung's disease caused death in early infancy. Operations were performed in 59 cases.

Three different types of operation were used. Abdomino-anal resection (Swenson, 1950), abdominal resection (Rehbein, 1958), and abdominoperineal resection (Duhamel, 1960).

Most of the patients were under 2 years of age at the time of the operation. In infants under 12 months of age the Swenson procedure was carried out five times and the Duhamel operation 10 times; three of these operations were performed on cases under the age of 6 months (Table 1).

A decompressive colostomy was done in 15 cases, but was used more rarely after the Duhamel operation became the routine (Tables 2 and 3 ). There has been no operative mortality. Three patients operated on by the Swenson method died later because of postoperative complications. In one case there was intestinal obstruction due to adhesions six months after the resection, in the second case the postoperative septicaemia caused encephalitis, and the patient died three months after the primary operation. In the third case a recto-urethral fistula was found three months after operation. A second pull-through operation four years after the primary operation was followed by a lethal peritonitis due to ischaemic necrosis of the distal colon.

The case in the series of Duhamel operations was an infant 2 weeks old, operated on for diffuse peritonitis. An aganglionic segment consisted of the distal colon up to the transverse colon, and there were two perforations in the middle of the descending colon. The Duhamel procedure was followed, but the patient died 11 days later, mainly because of

* Paper read at a meeting of the British Association of Paediatric Surgeons in Stockholm, September 1961. a severe infection. At autopsy peritonitis was regarded as the cause of death.

After the Swenson operation there were numerous complications, mostly due to leakage at the site of anastomosis. The leakage caused infections, such as pelvic abscesses, peritonitis and septicaemia. An anastomotic stricture developed postoperatively in six cases, but it was easily treated by dilatation.

TABLE 1

AGE DISTRIBUTION AT OPERATION

\begin{tabular}{ll|c|c|c|c|c}
\hline \multirow{2}{*}{ Operation } & $\begin{array}{c}\text { No. } \\
\text { of } \\
\text { Cases }\end{array}$ & \multicolumn{4}{|c|}{ Age (years) } \\
\cline { 3 - 6 } & & $0-1$ & $1-2$ & $2-7$ & $7-15$ \\
\hline Swenson (1950) &. & 28 & 5 & 16 & 5 & 2 \\
Rehbein (1958) & $\cdots$ & 8 & 2 & 2 & 3 & 1 \\
Duhamel (1960) & $\cdots$ & 26 & 10 & 8 & 4 & 4 \\
\hline
\end{tabular}

TABLE 2

PATIENTS WITH DECOMPRESSIVE COLOSTOMY BEFORE OPERATION

\begin{tabular}{lll|c|c}
\hline \multicolumn{2}{c|}{ Operation } & & No. of Cases & Colostomy \\
\hline Swenson (1950) & $\ldots$ &. & 28 & 11 \\
Rehbein (1958) & $\cdots$ & $\cdots$ & 8 & 1 \\
Duhamel (1960) & $\cdots$ & $\cdots$ & 26 & 3 \\
\hline
\end{tabular}

TABLE 3

COMPLICATIONS AFTER OPERATION

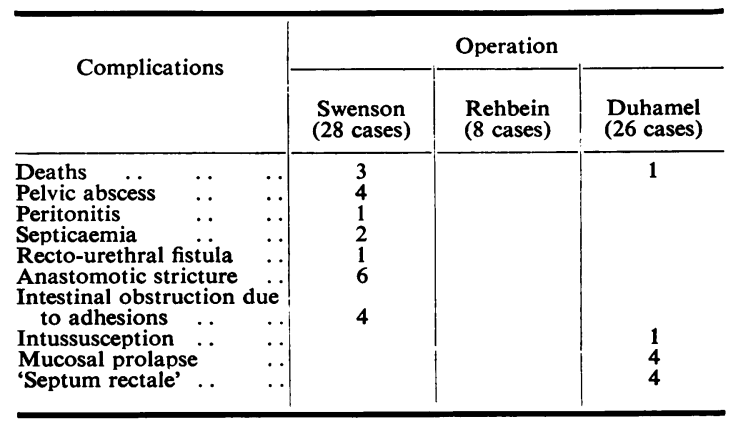


TABLE 4

RESULTS AND TIME OF FOLLOW-UP EXAMINATION

\begin{tabular}{|c|c|c|c|c|c|c|c|c|c|c|c|}
\hline \multirow{2}{*}{\multicolumn{2}{|c|}{ Operation }} & \multirow{2}{*}{$\begin{array}{c}\text { No. } \\
\text { of } \\
\text { Cases }\end{array}$} & \multicolumn{4}{|c|}{ Results } & \multicolumn{5}{|c|}{ Follow-up (years) } \\
\hline & & & Symptomless & Recurrence & Constipation & Soiling & $0-1$ & $1-3$ & $3-5$ & $5-10$ & $>10$ \\
\hline $\begin{array}{l}\text { Swenson (1950) } \\
\text { Rehbein (1958) } \\
\text { Duhamel (1960) }\end{array}$ & $\begin{array}{l}\cdots \\
\cdots \\
\cdots\end{array}$ & $\begin{array}{r}25 \\
8 \\
25\end{array}$ & $\begin{array}{r}18 \\
5 \\
15\end{array}$ & $\begin{array}{l}2 \\
1\end{array}$ & 3 & $\begin{array}{r}2 \\
2 \\
10\end{array}$ & 16 & $\begin{array}{l}1 \\
3 \\
9\end{array}$ & $\begin{array}{l}4 \\
5\end{array}$ & 16 & 4 \\
\hline
\end{tabular}

After the Duhamel procedure one intussusception developed nine days after operation. It was the only intra-abdominal complication with the exception of the primary perforation peritonitis mentioned earlier. In four cases mucosal prolapse was later trimmed off, and in four cases it was necessary to clamp a secondary septum in the rectal cavity with Kocher's forceps.

Follow-up examinations (Table 4) were made this year. Most operations by Swenson's method were done more than five years ago, and those by Duhamel's procedure less than three years ago.

There were two recurrences in the cases operated on by the Swenson method, probably due to too short a resection. One recurrence after the Rehbein procedure was probably due to the same reason. A secondary resection according to Duhamel was successfully done in all these cases.

Constipation was present in three cases after the Swenson operation and laxatives and enemas were needed. The constipation might have been a sign of a mild relapse. The Swenson operations were done in the early cases, and higher resections were used later.

Soiling has been seen fairly often in cases operated on by Duhamel's method. However, most of the patients are still under 4 years of age, and the soiling may be partly considered as an adaptation disturbance which is probably not permanent.

Our experience is that rectosigmoidectomy according to Duhamel is a technically easy operation and practically free from the risk of complications even in early infancy. A decompressive colostomy is therefore seldom needed. As soiling has not been a difficult problem in the treatment, the results of the operations have been considered satisfactory.

\section{REFERENCES}

Duhamel, B (1960) A new operation for the treatment of Hirschsprung's disease. Arch. Dis. Childh., 35, 38

Rehbein, F. (1958). Intraabdominelle Resektion oder RectoSigmoidektomie (Swenson) bei der Hirschsprungschen Krankheit? Chirurg., 29, 366

Swenson, O. (1950). A new surgical treatment for Hirschsprung's disease. Surgery, 28, 371 . 